\title{
Heterogeneity and Colonial Governance
}

\author{
Nobuhiro Mizuno \\ Faculty of Commerce and Economics, Chiba University of Commerce, Chiba, Japan \\ Email: nobu.mizuno8@gmail.com
}

Received 18 March 2015; accepted 12 April 2015; published 17 April 2015

Copyright (C) 2015 by author and Scientific Research Publishing Inc.

This work is licensed under the Creative Commons Attribution International License (CC BY).

http://creativecommons.org/licenses/by/4.0/

(c) (i) Open Access

\begin{abstract}
Some existing studies argue that indirect colonial rule adversely affects postcolonial development. To analyze the situation under which a colonial power adopts indirect rule to govern a colony, we analyze a delegation model wherein the colonial power decides whether to delegate policy choice to an agent who has an information advantage but has different policy preferences from that of the colonial power. The colonial power decides whether to delegate policy choice in multiple districts, and can acquire information by paying a cost in each district. We show that colonial powers are prone to adopt indirect rule when the heterogeneity among districts is high. The results are a possible explanation for why colonial powers utilized indirect rule in Africa, a region with high levels of ethnic diversity.
\end{abstract}

\section{Keywords}

Colonial Rule, Delegation, Heterogeneity

\section{Introduction}

Developing countries experienced divergent economic development paths during the last half of the twentieth century: while some Asian countries experienced rapid growth, the economies in most Sub-Saharan African countries stagnated. Recent research has revealed that colonial experience is a critical factor in such divergent development experiences. In particular, direct and indirect colonial rules have entirely different effects on postcolonial development. While direct rule, under which colonial powers build centralized governing structures to dominate entire region of colonies, favors postcolonial development by leaving effective state capacity, indirect colonial rule, under which autonomous governing power is delegated to indigenous rural elites, harms state building and growth after independence [1]-[4]. This raises a natural question: what is the source of such divergent forms of colonial governance? ${ }^{1}$

Sub-Saharan Africa has two notable features. The first feature is that most African colonies were ruled

${ }^{1}$ Gerring, Ziblatt, Van Gorp, and Arévalo [5] empirically show that indirect rule is prone to occur in regions where political organizations had developed prior to colonial rule. 
through indirect rule [6]. The second feature is its high level of ethnic diversity [7]. Thus, countries in SubSaharan Africa comprise heterogeneous ethnic groups with varying norms, cultures, and rules to solve disputes.

This paper provides a simple theoretical logic that links a colony's heterogeneity and the form of governance by colonial powers. We incorporate two features into a standard delegation model in which a principal decides whether to delegate policy choice to an agent who has information advantage but has different policy preferences from that of the principal (See [8] for a review of the delegation models of this type. Bendor and Meirowitz [9] provide both general treatment and many extensions of this type of delegation models.). First, a principal (a colonial power) decides whether to delegate policy choice in multiple districts. Second, the principal can acquire information on the realized value of unobservable policy shock in each district. Homogeneity of a colony is modeled by correlation among policy shocks in the districts. When the degree of heterogeneity is large, the information acquired in a district is less useful to govern another district. In this situation, if the uncertainty about policy outcomes is considerably large, directly governing the colony is costly for the colonial power, and thus indirect rule is adopted.

\section{The Model}

Consider a colony with two districts: districts 1 and 2. Indigenous agents implement policies in each district. We call the indigenous agent in district $i$ agent $i$, where $i \in\{1,2\}$. In direct rule, a colonial power chooses policies to be implemented in each district and instructs each indigenous agent to implement the policies. In indirect rule, the colonial power delegates policy choice in district $i$ to agent $i$.

In district $i$, policy outcome $x_{i} \in \mathcal{R}$ depends on the policy choice $p_{i} \in \mathcal{R}$ and a random shock $\epsilon_{i}$. We assume that $x_{i}=p_{i}+\epsilon_{i}$. In this environment, observation of the realized value of $\epsilon_{i}$ enables the policy maker to achieve his/her ideal point. The possible realized value of $\epsilon_{i}$ is either $-\epsilon<0$ or $\epsilon>0$, and $P\left(\epsilon_{i}=-\epsilon\right)=P\left(\epsilon_{i}=\epsilon\right)=1 / 2$.

Furthermore, the two random variables correlate with each other. We assume that

$P\left(\epsilon_{i}=\epsilon \mid \epsilon_{j}=\epsilon\right)=P\left(\epsilon_{i}=-\epsilon \mid \epsilon_{j}=-\epsilon\right)=1 / 2+q$, where $q \in[0,1 / 2]$. The parameter $q$ represents the degree of homogeneity between the two districts. As $q$ becomes larger, the two districts are more likely to have similar policy environments, and are more homogeneous with each other. Hence, a small value of $q$ means that the two districts are heterogeneous. Indigenous agent $i$ can observe the realization of $\epsilon_{i}$. The colonial power can observe the realization of $\epsilon_{i}$ by paying the cost of information acquisition $c>0$.

The payoff that the colonial power obtains in district $i$ is $u_{c i}=-\left|x_{i}\right|-I_{i} c$, where $I_{i}$ equals one if the colonial power acquires information in district $i$ and equals zero otherwise. The total payoff of the colonial power is $u_{c 1}+u_{c 2}$. The payoff of the indigenous agent $i$ is $u_{i}\left(x_{i}\right)=-\left|x_{i}-x_{A}\right|$. We assume that $x_{A}>0$.

Decision making in district 1 precedes that in district 2 . The timing of events in each district is as follows:

1) The colonial power decides whether to delegate policy choice to agent $i$.

2) The value of $\epsilon_{i}$ is realized.

3) If no delegation occurs, then the colonial power decides whether to acquire the information on the realized value of $\epsilon_{i}$.

4) Either the colonial power or agent $i$ chooses policy $p_{i}$.

We derive the subgame perfect equilibrium of this game. In the following, we assume that the cost of information acquisition is sufficiently large. Under this assumption, the colonial power never chooses to acquire information in district 2 .

\section{Assumption 1}

$$
-c<-x_{A} .
$$

\section{Analysis}

\subsection{Policy Choice in District 2}

First consider the case where the colonial power delegates the policy choice to indigenous agent 2 . Because the indigenous agent can observe the realized value of $\epsilon_{2}$, agent 2 can realize his/her ideal point $x_{A}$ by choosing $p_{2}=x_{A}-\epsilon_{2}$. In this case, the colonial power obtains $-x_{A}$ from district 2 .

\footnotetext{
${ }^{2}$ The following environment is based on Chapter 5 of [10].
} 
Next, consider the case where the colonial power does not delegate the policy choice and acquires information on the realized value of $\epsilon_{2}$. In this case, the colonial power can realize its ideal point 0 by choosing $p_{2}=-\epsilon_{2}$; however, it incurs the cost of information acquisition $-c$. Thus, the payoff that the colonial power obtains in district 2 is $-c$.

When the colonial power neither delegates the policy choice nor acquires information, its payoff in district 2 depends on whether the colonial power has acquired information on $\epsilon_{1}$ in district 1 . If the colonial power does not have information on the realized value of $\epsilon_{1}$, then any policy in $[-\epsilon, \epsilon]$ is optimal, and the colonial power obtains $-\epsilon$ from district 2 .

In the case where the colonial power knows that $\epsilon_{1}=\epsilon, \quad p\left(\epsilon_{2}=\epsilon \mid \epsilon_{1}=\epsilon\right)=1 / 2+q$ and $p\left(\epsilon_{2}=-\epsilon \mid \epsilon_{1}=\epsilon\right)=1 / 2-q$. Thus, the colonial power's payoff from $p_{2}$ can be written as $-\left(\frac{1}{2}+q\right)\left|p_{2}+\epsilon\right|-\left(\frac{1}{2}-q\right)\left|p_{2}-\epsilon\right|=-2 q p_{2}-\epsilon .^{3}$ Hence, the colonial power chooses $p_{2}=-\epsilon$ and obtains $(2 q-1) \epsilon \in[-\epsilon, 0]$. Similarly, the colonial power who obtains information that $\epsilon_{1}=-\epsilon$ chooses $p_{2}=\epsilon$ and obtains $(2 q-1) \epsilon$.

\subsection{Delegation Choice in District 2}

From the results in the previous section, in the case where the colonial power does not know the realized value of $\epsilon_{1}$, the colonial power delegates the policy choice if and only if $-x_{A}>-\epsilon .{ }^{4}$ In the case where the colonial power knows the realized value of $\epsilon_{1}$, the colonial power delegates the policy choice if and only if $-x_{A}>(2 q-1) \epsilon$.

\subsection{Policy Choice in District 1}

The policy choice in district 1 is similar to that in district 2. If the colonial power delegates the policy choice, then it obtains $-x_{A}$. If the colonial power directly chooses a policy without acquiring information on $\epsilon_{1}$, then it obtains $-\epsilon$. If the colonial power directly chooses a policy with information, then it obtains $-c$.

\subsection{Equilibrium}

To derive the equilibrium, we first show the following preliminary results.

Lemma 1 If the colonial power delegates policy choice in district 1, then it delegates policy choice in district 2.

Proof. See Appendix.

Lemma 2 If the colonial power directly chooses a policy without acquiring information in district 1 , then it does so in district 2.

Proof. See Appendix.

Lemma 3 If the colonial power acquires information in district 1, it directly chooses a policy without acquiring information in district 2.

Proof. See Appendix.

From the above results, depending on the values of parameters, three equilibrium-governance patterns are possible:

1) The colonial power delegates the policy choice in both districts.

2) The colonial power directly chooses policies without acquiring information in both districts.

3) The colonial power acquires information in district 1 and directly chooses policies in both districts.

Case 1 can be interpreted as indirect rule, and cases 2 and 3 are direct rules. The colonial power chooses a governance strategy that provides the maximum payoff. The colonial power obtains $-2 x_{A}$ in case 1 , $-2 \epsilon$ in case 2 , and $-c+(2 q-1) \epsilon$ in case 3 . Thus, the colonial power chooses indirect rule if and only if

$$
-2 x_{A} \geq \max \{-2 \epsilon,-c+(2 q-1) \epsilon\},
$$

which can be rewritten as

\footnotetext{
${ }^{3}$ Since choosing $p_{2}>\epsilon$ and choosing $p_{2}<-\epsilon$ are suboptimal for the colonial power, the equilibrium policy satisfies $p_{2} \in[-\epsilon, \epsilon]$.

${ }^{4}$ We assume that $x_{A} \neq \epsilon$ for simplicity.
} 


$$
x_{A} \leq \min \left\{\epsilon, \frac{c+(1-2 q) \epsilon}{2}\right\} .
$$

The degree of homogeneity $q$ affects the form of governance when the degree of policy uncertainty is sufficiently high: $\epsilon>c /(2 q+1)$. Thus, we can derive the following proposition.

Proposition 1 Assume that the degree of policy uncertainty $\epsilon$ is greater than $c /(2 q+1)$. Then, the colonial power is prone to choose indirect rule in the following situations:

- The cost of information acquisition $c$ is large.

- The policy preferences of indigenous agents are close to that of the colonial power ( $x_{A}$ is small).

- The policy uncertainty $\epsilon$ is large.

- The degree of homogeneity between districts $q$ is small.

When the degree of heterogeneity is larger (i.e., $q$ is smaller), information acquired in district 1 is less useful to govern district 2. In this situation, if the uncertainty about policy outcomes $\epsilon$ is large, then directly governing the colony is costly for the colonial power, and indirect rule is adopted.

\section{Conclusion}

To analyze the situation under which the colonial power adopts indirect rule to govern a colony, we analyze a delegation model wherein the colonial power decides whether to delegate policy choice to an agent who has an information advantage but has different policy preferences from that of the colonial power. The colonial power decides whether to delegate policy choice in multiple districts, and can acquire information by paying a cost in each district. We show that colonial powers are prone to adopt indirect rule when the heterogeneity among districts is high. The results are a possible explanation for why colonial powers utilized indirect rule in Africa, a region with high level of ethnic diversity.

\section{Acknowledgements}

I thank the referee for his/her comments.

\section{References}

[1] Kohli, A. (1994) Where Do High Growth Political Economies Come from? The Japanese Lineage of Korea's “Developmental State”. World Development, 22, 1269-1293. http://dx.doi.org/10.1016/0305-750X(94)90004-3

[2] Kohli, A. (2004) State-Directed Development: Political Power and Industrialization in the Global Periphery. Cambridge University Press, New York. http://dx.doi.org/10.1017/CBO9780511754371

[3] Lange, M.K. (2004) British Colonial Legacies and Political Development. World Development, 32, 905-922. http://dx.doi.org/10.1016/j.worlddev.2003.12.001

[4] Lange, M. (2009) Lineages of Despotism and Development: British Colonialism and State Power. University of Chicago Press, Chicago. http://dx.doi.org/10.7208/chicago/9780226470702.001.0001

[5] Gerring, J., Ziblatt, D., Van Gorp, J. and Arévalo, J. (2011) An Institutional Theory of Direct and Indirect Rule. World Politics, 63, 377-433. http://dx.doi.org/10.1017/S0043887111000104

[6] Mamdani, M. (1996) Citizen and Subject: Contemporary Africa and the Legacy of Late Colonialism. Princeton University Press, Princeton.

[7] Easterly, W. and Levine, R. (1997) Africa’s Growth Tragedy: Policies and Ethnic Divisions. Quarterly Journal of Economics, 112, 1203-1250. http://dx.doi.org/10.1162/003355300555466

[8] Bendor, J., Glazer, A. and Hammond, T. (2001) Theories of Delegation. Annual Review of Political Science, 4, 235269. http://dx.doi.org/10.1146/annurev.polisci.4.1.235

[9] Bendor, J. and Meirowitz, A. (2004) Spatial Models of Delegation. American Political Science Review, 98, $293-310$. http://dx.doi.org/10.1017/S0003055404001157

[10] Gehlbach, S. (2013) Formal Models of Domestic Politics. Cambridge University Press, New York. http://dx.doi.org/10.1017/CBO9781139045544 


\section{Appendix}

\section{Proof of Lemma 1}

Proof. To show the contradiction, assume that the colonial power delegates policy choice only in district 1 . In this case, the colonial power obtains $-x_{A}-\epsilon$ from the two districts. ${ }^{5}$ Because the colonial power chooses not to delegate in district $2,-x_{A}<-\epsilon$. The colonial power can obtain $-2 \epsilon$ by directly choosing policies in both districts, which is greater than $-x_{A}-\epsilon$. This contradicts the fact that $-x_{A}-\epsilon$ is the payoff from the optimal decision by the colonial power.

\section{Proof of Lemma 2}

Proof. Assume that the colonial power directly chooses a policy without acquiring information in district 1 and delegates the policy choice in district 2. The colonial power obtains $-\epsilon-x_{A}$. Because the colonial power chooses delegation in district $2,-x_{A}>-\epsilon$. If the colonial power delegates in both districts, then it obtains $-2 x_{A}$, which is greater than $-\epsilon-x_{A}$. This is a contradiction.

Proof of Lemma 3

Proof. Assume that the colonial power acquires information in district 1 and delegates the policy choice in district 2. Then, the colonial power obtains $-c-x_{A}$. If the colonial power chooses delegation in both districts, then it obtains $-2 x_{A}$, which is greater than $-c-x_{A}$ from Assumption 1. This is a contradiction. 